\title{
Dextran Sulfate/Pramlintide Polyelectrolyte Nanoparticles as a Promising Delivery System: Optimization, Evaluation of Supramolecular Interactions and Effect on Conformational Stability of the Peptide Drug
}

\author{
Carine Zuglianello, ${ }^{\circledR a}$ Andrés F. Chamorro, ${ }^{b}$ Vanessa A. de Oliveira, ${ }^{c}$ \\ Francisco H. Xavier Júniord and Elenara Lemos-Senna ${ }^{\circledR} * a$
}

\begin{abstract}
aPrograma de Pós-Graduação em Nanotecnologia Farmacêutica, Departamento de Ciências Farmacêuticas, Universidade Federal de Santa Catarina, Campus Trindade, 88040-900 Florianópolis-SC, Brazil
\end{abstract}

${ }^{b}$ Programa de Pós-Graduação em Química, Departamento de Química, Universidade Federal de Santa Catarina, Campus Trindade, 88040-900 Florianópolis-SC, Brazil

\author{
${ }^{c}$ Laboratório Central de Biologia Molecular e Estrutural, Universidade Federal de Santa Catarina, \\ Campus Trindade, 88040-900 Florianópolis-SC, Brazil
}

${ }^{d}$ Laboratório de Biotecnologia Farmacêutica, Departamento de Ciências Farmacêuticas, Universidade Federal da Paraíba, 58051-900 João Pessoa-PB, Brazil

\begin{abstract}
In this study, we investigated the feasibility to obtain nanoparticles (NPs) by assembling pramlintide (Pram) with dextran sulfate (DexS), as a new approach for mucosal peptide delivery. DexS/Pram NPs were prepared by dropwise addition of a Pram solution to a DexS solution under magnetic stirring. The physicochemical characteristics of NPs and molecular interactions involved in the co-assembling were evaluated by dynamic light scattering (DLS), transmission electronic microscopy (TEM), isothermal titration microcalorimetry, Fourier-transform infrared spectroscopy (FTIR), fluorescence quenching, and circular dichroism (CD). DexS/Pram NPs displayed a narrow size distribution (ca. $200 \mathrm{~nm}$ ), negative zeta potential (ca. $-40 \mathrm{mV}$ ), association efficiency close to $100 \%$, and nanogel behavior. The assembling with DexS increased the Pram $\alpha$-helical content, stabilizing the peptide in its bioactive form. The colloidal stability of nanoparticles was dependent on the salt concentration and it could be assumed that peptide release from nanoparticles occurs by dissociation of the complex at physiological conditions.
\end{abstract}

Keywords: pramlintide, dextran sulfate, polyelectrolyte nanoparticles, supramolecular interactions, peptide drug delivery

\section{Introduction}

Pramlintide acetate (Pram) is an analog peptide drug of amylin (also known as human islet amyloid polypeptide), which has been approved for clinical use for the treatment of type 1 and type 2 diabetes in patients who did not reach a satisfactory glycemic control, even though insulin therapy was thoroughly adjusted. ${ }^{1}$ Pram differs from human amylin by the replacement of amino acids alanine, serine, and serine at positions 25,28 and 29 , respectively, by proline. It retains its biological potency but prevents self-aggregation and provides a higher aqueous solubility than human amylin. These changes were inspired by the discovery of

*e-mail: lemos.senna@ufsc.br lesser amyloidogenic murine amylin. ${ }^{2}$ The advantageous property of Pram for therapeutic applications is that it avoids the formation of extracellular amyloid deposits, responsible for the development of pancreatic $\beta$-cell disfunction and death, characteristic of the pathogenesis of type 2 diabetes. ${ }^{3}$ Pram acts by lowering postprandial glucagon secretion, inhibiting gastric emptying and giving a sensation of satiety by interacting with the hypothalamic receptors in the brain. ${ }^{4}$ Also, anti-obesity, ${ }^{5}$ antitumoral, ${ }^{6,7}$ and neuroprotective activities ${ }^{8,9}$ have also been described for this peptide drug.

Despite retaining all of the beneficial actions of native amylin without the disadvantages of amyloid formation and cytotoxicity, pramlintide still has solubility issues, particularly at physiological $\mathrm{pH}$, exhibiting a higher 
solubility at acidic $\mathrm{pH}$, at which the $\mathrm{N}$-terminus and His- 18 are fully protonated. This property prevents co-formulation with insulin, which is formulated at near-neutral $\mathrm{pH}$, leading to increased cost in combination therapies and potentially reducing patient compliance due to the need for multiple injections. ${ }^{10,11}$ In this regard, the development of dosage forms intended to deliver pramlintide across the epithelial mucosa, e.g., buccal, nasal, and pulmonary mucosae, and may represent an alternative approach to avoid the use of invasive parenteral routes. ${ }^{12}$ However, the development and production of peptide and protein drug products are also a challenge since aggregation can take place in several industrial processes or storage conditions, leading to the formation of larger species consisting of multiple polypeptide chains. The physical stability reduction of peptide drugs leads not only to a loss in activity but also to the increases in toxicity and immunogenicity. ${ }^{12,13}$ With this respect, the use of strategies to stabilize peptides in the helical conformation may reduce their conformational heterogeneity, increasing their resistance to enzymatic degradation and maintaining their therapeutic functionality. ${ }^{13,14}$

A variety of nanocarrier delivery systems has been proposed to overcome the limitations of delivering therapeutic peptides. However, the eligibility of a nanocarrier for the association of a peptide drug depends on several peptide characteristics such as molecular dimension, electrostatic effects, stability, polarity, solubility, and surface activity. ${ }^{15}$ Moreover, an ideal delivery system should provide a high peptide payload, optimal stability, batch reproducibility and scale-up, and tailorable release profile. ${ }^{16}$ With this regard, polyelectrolytes have been successfully used to form nanocomplex assemblies with many peptides, playing an important role in various platforms relating to the delivery of peptide-based drugs. ${ }^{17}$ The assembly occurs by weak and polyvalent interactions, rather than covalent bonds, bridging individual building blocks and guiding the formation of a thermodynamically stable nanocomplex. ${ }^{18}$ In particular, polyelectrolyte nanoparticles may offer an interesting approach for delivering peptides by mucosal routes since they could control the drug release, improve macromolecule stability, avoid enzymatic degradation, and improve retention and permeability by promoting intimate interaction with the mucosal epithelium. ${ }^{19}$
According to the previous studies, the $N$-terminal amino group and the side chain of the lysine-1 residue (K-1), and the side chains of arginine-11 (R-11) and histidine-18 $(\mathrm{H}-18)$ residues of Pram are protonated at acidic $\mathrm{pH} .{ }^{20,21}$ Also, computational simulation of its molecular structure indicated that Pram displays four positively charged amine groups at $\mathrm{pH} 4.0$ (Figure 1). Then, we have hypothesized that polyelectrolyte nanoparticles can be obtained by the interaction of pramlintide with negatively charged polysaccharides and that it can be exploited as a new drug delivery system for delivery of this peptide through mucosal surfaces. Dextran sulfate (DexS) is a semisynthetic sulfated polysaccharide derived from dextran, in which sodium sulfate groups $\left(-\mathrm{OSO}_{3} \mathrm{Na}\right)$ are attached to each $(1 \rightarrow 6)$ - $\alpha$-linked anhydroglucose unit. ${ }^{22}$ Interactions of DexS with proteins have been reported in the literature for both protein drug delivery and protein stabilization purposes. ${ }^{23}$ The approach to obtain polyelectrolyte nanoparticles for delivery of Pram is described for the first time in the literature.

\section{Experimental}

\section{Materials}

Pramlintide acetate (Pram, $>95.2 \%$ purity, weightaverage molecular weight $\left.\left(\mathrm{M}_{\mathrm{w}}\right) 3,951.4\right)$ was obtained from Genemed Syn (lot No. 108695, Genemed Synthesis, Texas, USA). Dextran sodium sulfate (DexS) (relative molecular weight $\left(\mathrm{M}_{\mathrm{r}}\right) 40,000$; with a sulfur content of $17.6 \%$, according to the supplier specification sheet) and fluorescamine (Fluram, BioReagent, suitable for fluorescence, $\geq 99.0 \%$ ) were supplied by Sigma-Aldrich (São Paulo, Brazil). Acetonitrile (HPLC grade, Honeywell) and trifluoroacetic acid (HPLC grade, Fisher Chemical) were purchased from Navelab (Curitiba, Brazil). All other solvents and reagents were of analytical grade and used without further purification. Stock solutions of Pram and DexS were prepared using acidified ultrapure water (Milli-Q).

\section{Physicochemical characterization of DexS}

DexS was characterized by high-performance size exclusion chromatography (HPSEC) using a

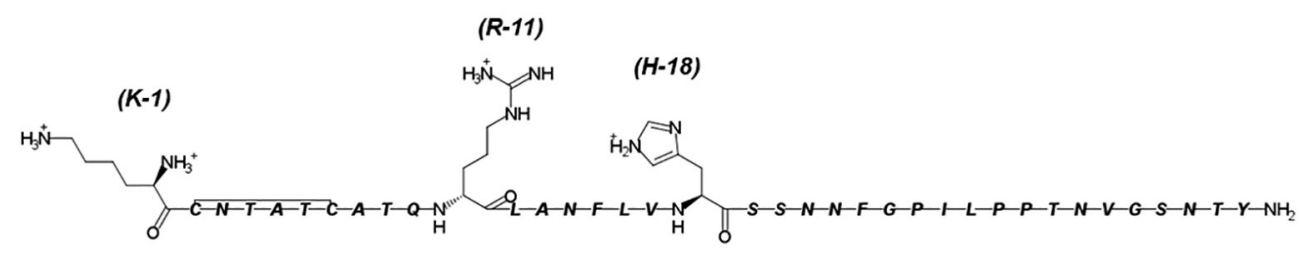

Figure 1. Fully protonated Pram sequence exhibiting the positively charged $N$-terminal amino group, side chain of the lysine-1 (K-1), the positively charged side chains of arginine-11 (R-11), and histidine-18 (H-18) at $\mathrm{pH}<4.0$ (drawn with Marvin Sketch 19.18.0, ChemAxon). ${ }^{24}$ 
Viscotek-HPSEC multidetector system (Malvern Instruments, Worcestershire, UK) equipped with a Shodex OHpak SB-806 HQ column (Showa Denko America, New York, NY, USA), connected in series and coupled to a differential refractometer (Viscoteck VE3580 RI detector), a viscometric detector and a laser light scattering detector (model 270 dual detector) with low angle $7^{\circ}$ (LALLS) and right angle $90^{\circ}$ (RALLS) lasers with $\lambda 632.8 \mathrm{~nm}$. The analyses were carried out at $40{ }^{\circ} \mathrm{C}(313.15 \mathrm{~K})$ using $0.1 \mathrm{~mol} \mathrm{~L}^{-1}$ sodium nitrate containing $200 \mathrm{ppm}$ sodium azide as a mobile phase and a flow rate of $0.4 \mathrm{~mL} \mathrm{~min}^{-1}$.

\section{Preparation of DexS/Pram polyelectrolyte nanoparticles (DexS/Pram NPs)}

DexS/Pram NPs were prepared by dropwise addition of different volumes of a Pram solution $\left(2.50 \times 10^{-4} \mathrm{~mol} \mathrm{~L}^{-1}\right.$, in $1.00 \times 10^{-3} \mathrm{~mol} \mathrm{~L}^{-1}$ acetic acid, $\mathrm{pH}$ ca. 4.0) to a DexS solution $\left(1.20 \times 10^{-5} \mathrm{~mol} \mathrm{~L}^{-1}\right)$ under constant magnetic stirring (ca. $600 \mathrm{rpm}$, Multistirrer 15, Velp Scientifica, Italy) at room temperature. DexS/Pram NPs were produced at molar ratios from $2.40 \times 10^{-2}$ to $5.30 \times 10^{-2}$. The colloidal dispersions were stored at $8{ }^{\circ} \mathrm{C}$ at least for $12 \mathrm{~h}(281.15 \mathrm{~K}, 43,200 \mathrm{~s})$ before analysis. All DexS/Pram NPs were prepared in triplicate.

\section{Characterization of DexS/Pram polyelectrolyte nanoparticles}

\section{Hydrodynamic particle size}

The size distribution, mean particle size, and polydispersity index (PdI) were determined by dynamic light scattering (DLS) using Zetasizer Nano ZS equipment (Malvern Instruments, Worcestershire, UK). The measurements were made after appropriate dilution of DexS/Pram NPs in ultrapure water at a fixed scattering angle of $173^{\circ}$. Size distribution was also analyzed at scattering angles varying from 30 to $145^{\circ}$, using an ALV laser goniometer (AVL-Laser, Germany) equipped with a $35 \mathrm{~mW}$ red helium-neon linearly polarized laser $(\lambda=632.8 \mathrm{~nm})$ and multiple-tau digital correlator (LSE-5004). ALV-correlator software version 3.0 was used to obtain the DLS autocorrelation functions $\mathrm{g}^{(1)}(\mathrm{q}, \mathrm{t}){ }^{25}$ The distribution function of the decay time $\mathrm{A}(\mathrm{t})$ and the distribution function of size $A\left(R_{h}\right)$ were obtained by CONTIN analysis of the $\mathrm{g}^{(1)}(\mathrm{q}, \mathrm{t})$ function. The hydrodynamic radii of the nanoparticles $\left(\mathrm{R}_{\mathrm{h}}^{\mathrm{NP}}\right)$ were calculated using the EinsteinStokes equation (equation 1).

$\mathrm{R}_{\mathrm{h}}^{\mathrm{NP}}=\frac{\mathrm{kT}}{6 \pi \eta \mathrm{D}^{\mathrm{NP}}}$

where $\mathrm{T}$ is absolute temperature, $\mathrm{k}$ the Boltzmann constant,
$\mathrm{D}^{\mathrm{NP}}$ the diffusion coefficient of the aggregate and $\eta$ the water viscosity. ${ }^{26}$ Analyses were conducted in triplicate.

\section{Zeta potential}

Zeta potential was determined by laser-doppler anemometry using a Zetasizer Nanoseriers (Malvern Instruments, Worcestershire, UK). DexS/Pram NPs were diluted in ultrapure water and placed in an electrophoretic cell where a potential of $\pm 150 \mathrm{mV}$ was established. The zeta potential values were obtained by the equipment software from the mean electrophoretic mobility using Smoluchowski's equation. ${ }^{27}$

\section{Nanoparticle morphology}

The morphological examination of DexS/Pram NPs was performed using a JEM-1011 transmission electron microscope (Jeol, Japan), operating at $100 \mathrm{kV}$. Drops of the colloidal dispersions were deposited in formvar/carbon copper grids and left to dry for $10 \mathrm{~min}(600 \mathrm{~s})$. The samples were then negatively stained with $1.0 \%$ phosphotungstic acid $(\mathrm{m} / \mathrm{v})$ and left to dry overnight under vacuum. Transmission electron microscopy (TEM) images were obtained and ImageJ software was also used to measure particle size. ${ }^{28}$

\section{Association efficiency}

Free Pram was separated from DexS/Pram NPs by ultracentrifugation at $40,000 \mathrm{~g}$ for $30 \mathrm{~min}$ at $4{ }^{\circ} \mathrm{C}(1,800 \mathrm{~s}$, $277.15 \mathrm{~K})$ using an Optima Max-XP ultracentrifuge (Beckman Coulter, USA). The supernatants were collected and free Pram was determined by fluorescamine assay, ${ }^{29}$ using an analytical curve constructed with Pram at concentrations ranging from $8.00 \times 10^{-3}$ to $4.80 \times 10^{-2} \mathrm{mg} \mathrm{mL}^{-1},(y=0.057 x+0.367$, correlation coefficient, $r>0.999$ ). Free Pram was used as control. The association efficiency (\%) was estimated as the mass percentage of Pram that formed polyelectrolyte nanoparticles relative to the initial amount of peptide added. The analyses were performed in triplicate.

\section{Investigation of DexS/Pram interactions}

\section{Fluorescence quenching}

Fluorescamine assay was used to investigate the molecular interactions between DexS and Pram in DexS/ Pram NPs. Briefly, DexS/Pram complexes corresponding to a constant Pram concentration of $7.25 \times 10^{-5} \mathrm{~mol} \mathrm{~L}^{-1}$ and DexS concentrations ranging from 0 to $3.25 \times 10^{-6} \mathrm{~mol} \mathrm{~L}^{-1}$ were both prepared in $1.00 \times 10^{-3} \mathrm{~mol} \mathrm{~L}^{-1}$ acetic acid (pH ca. 4.0) in a 96-well black microplate and incubated for $60 \mathrm{~min}$ (final volume $0.15 \mathrm{~mL}, 3,600 \mathrm{~s}$ ). Then, $0.05 \mathrm{~mL}$ 
of a $0.50 \mathrm{mg} \mathrm{mL} \mathrm{m}^{-1}$ fluorescamine solution in dimethyl sulfoxide was added to each well and left to react for $10 \mathrm{~min}$ (600 s). The fluorescence emission was recorded using a Tecan Infinite M200 microplate reader in the wavelength interval 430-600 nm, with excitation settled at $390 \mathrm{~nm}$. Fluorescence suppression was fitted in the Stern-Volmer model, described by equation 2 .

$\frac{\mathrm{F}_{0}}{\mathrm{~F}}=1+\mathrm{K}_{\mathrm{SV}}[\mathrm{Q}]=1+\mathrm{K}_{\mathrm{q}} \tau_{0}[\mathrm{Q}]$

where $F_{0}$ and $F$ are the fluorescence intensity in the absence and presence of several concentrations of the DexS (fluorescence suppressor), respectively, $K_{\mathrm{SV}}$ is the Stern-Volmer constant, [Q] the molar concentration of suppressor agent, $\mathrm{K}_{\mathrm{q}}$ the suppression rate constant, and $\tau_{0}$ the polypeptide half-life in the absence of suppressor. DexS solutions at respective concentrations were used as control. Experiments were carried out in triplicate.

Isothermal calorimetry titration (ITC)

The affinity experiments used ITC200 equipment (GE Healthcare Life Sciences, Uppsala, Sweden). The titrations were performed by filling the ITC cell with a $1.20 \times 10^{-5} \mathrm{~mol} \mathrm{~L}^{-1}$ DexS solution and the syringe with a $2.50 \times 10^{-4} \mathrm{~mol} \mathrm{~L}^{-1}$ Pram solution. The first injection of $4.00 \times 10^{-4} \mathrm{~mL}$ was discarded to eliminate diffusion effects of material from the syringe to the sample cell. Experiments were set up with 19 consecutive injections $\left(2.00 \times 10^{-3} \mathrm{~mL}\right)$ with a duration of $5 \mathrm{~s}$ each and intervals of $150 \mathrm{~s}$, at a stirring speed of $400 \mathrm{rpm}$, and temperature fixed at $25{ }^{\circ} \mathrm{C}$ $(298.15 \mathrm{~K})$. Blank titrations were performed by adding Pram solution into the cell filled with $1.00 \times 10^{-3} \mathrm{~mol} \mathrm{~L}^{-1}$ acetic acid. Data analysis was performed by Origin 7.0 MicroCal iTC200 provided by MicroCal. ${ }^{30}$ The isotherm was established based on the integration of the obtained peaks by plotting the resulting heat values from each injection against the DexS/Pram molar ratio. Also, the heat of dilution was subtracted from the data considering the final points of the ITC experiments, in which no significant heat changes were observed. The thermodynamic parameters were determined using the One Set of Sites model that adjusts the curve by nonlinear regression (least-squares method). The thermodynamic relationships considered for this experiment are described in equation 3.

$\Delta \mathrm{G}=-\mathrm{RT} \ln \mathrm{K}_{\mathrm{a}}=\mathrm{RT} \ln \mathrm{K}_{\mathrm{d}}$

where $\Delta \mathrm{G}$ is the Gibbs free energy, $\mathrm{R}$ the universal gas constant, $\mathrm{T}$ the temperature, $\mathrm{K}_{\mathrm{a}}$ the association constant, and $\mathrm{K}_{\mathrm{d}}$ the dissociation constant.

\section{Fourier-transform infrared spectroscopy (FTIR)}

FTIR analyses were performed on the dry powder of DexS/Pram NPs, obtained by isolation of the pellet by ultracentrifugation of the formulations at $40,000 \mathrm{~g}$ for $30 \mathrm{~min}$ at $4{ }^{\circ} \mathrm{C}$ (Optima Max-XP, Beckman Counter, USA) $(1,800 \mathrm{~s}, 277.15 \mathrm{~K})$. Before analysis, the pellet was completely dried under vacuum for $24 \mathrm{~h}(86,400 \mathrm{~s})$. Spectra of Pram, DexS, and DexS/Pram NPs were obtained using an FTIR spectrophotometer (Frontier, PerkinElmer, Waltham, USA) in the scanning region of $1,000-1,800 \mathrm{~cm}^{-1}$ at a resolution of $2 \mathrm{~cm}^{-1}$. Second-derivative FTIR spectra were plotted.

\section{Circular dichroism (CD)}

Changes in Pram structure after its association with DexS (at DexS concentrations ranging from $4.00 \times 10^{-7}$ to $1.70 \times 10^{-6} \mathrm{~mol} \mathrm{~L}^{-1}$ and constant pramlintide concentration of $2.90 \times 10^{-5} \mathrm{~mol} \mathrm{~L}^{-1}$ ) were evaluated by $\mathrm{CD}$ using ultrapure water adjusted to $\mathrm{pH} 4.0$ as a diluent when freshly prepared samples were analyzed, and to $\mathrm{pH} 7.0$ for samples incubated for $24 \mathrm{~h}$ at $37^{\circ} \mathrm{C}(86,400 \mathrm{~s}, 310.15 \mathrm{~K})$. Free Pram was used as control. Measurements were performed in a Jasco J-815 spectropolarimeter at $25{ }^{\circ} \mathrm{C}(298.15 \mathrm{~K})$, at wavelength range $260-185 \mathrm{~nm}$ and cell length of $10 \mathrm{~mm}$, a bandwidth of $1.0 \mathrm{~nm}$, and a scan rate of $0.8 \mathrm{~nm} \mathrm{~s}^{-1}$. Analyses were performed in triplicate. Predictions of secondary structures from molar ellipticity in the wavelength range $240-190 \mathrm{~nm}$ were obtained using $\mathrm{k} 2 \mathrm{~d} 3$ webserver. ${ }^{31}$

\section{Colloidal stability and drug release}

The effect of the ionic strength of the medium on the aggregation of the nanoparticles and Pram dissociation was evaluated by diluting the colloidal dispersions in ultrapure water or $\mathrm{NaCl}$ solution at concentrations ranging from $1.00 \times 10^{-2}$ to $2.00 \times 10^{-1} \mathrm{~mol} \mathrm{~L}^{-1}$. The samples were analyzed according to size, polydispersity index, and zeta potential as described above. Pram dissociation was evaluated by incubating DexS/Pram NPs or free Pram at $1: 10(\mathrm{v} / \mathrm{v})$ dilution in saline solutions for $60 \mathrm{~min}(3,600 \mathrm{~s})$. The Pram release kinetics from nanoparticles was also evaluated after dilution of the samples in simulated nasal fluid (SNF, pH 5.5) $)^{32}$ or ultrapure water at 1:50 (v/v). Samples were then submitted to ultracentrifugation at $40,000 \mathrm{~g}, 4{ }^{\circ} \mathrm{C}$ for $30 \mathrm{~min}(277.15 \mathrm{~K}, 1,800 \mathrm{~s})$ in an Optima Max-XP ultracentrifuge (Beckman Coulter, USA). Supernatants were withdrawn and analyzed for Pram concentration by liquid chromatography with ultraviolet detection, using a Series 200 PerkinElmer HPLC system equipped with an autosampler, a binary pump, and a UV-Vis detector. The analyses were performed using a $\mathrm{C} 18$ column (Zorbax Eclipse Plus, $150 \times 4.6 \mathrm{~mm}, 5 \mu \mathrm{m}$ ) and a 
mobile phase consisting of acetonitrile with trifluoracetic acid $0.1 \%(\mathrm{v} / \mathrm{v})(\mathrm{A})$ and water with trifluoracetic acid $0.1 \%(\mathrm{v} / \mathrm{v})(\mathrm{B})$. The mobile phase was eluted at a flow rate of $1.0 \mathrm{~mL} \mathrm{~min} \mathrm{~m}^{-1}$ using a linear gradient program of 10 to $65 \%$ (A) over $25 \mathrm{~min}(1,500 \mathrm{~s})$. The injection volume of the samples was $2.00 \times 10^{-3} \mathrm{~mL}$ and detection was at $205 \mathrm{~nm}$. The Pram concentration was determined using an analytical curve constructed with Pram at concentrations ranging from $1.13 \times 10^{-2}$ to $4.52 \times 10^{-2} \mathrm{mg} \mathrm{mL}^{-1}(y=26794 x-36790$, $r=0.999)$.

\section{Results and Discussion}

\section{Physicochemical characterization of the DexS}

Since the properties of the polymers, especially the molecular weight, affect the formation of polyelectrolyte nanoparticles, DexS was characterized by HPSEC. According to the analysis, DexS presented a number average molecular weight $\left(\mathrm{M}_{\mathrm{n}}\right)$ and a weight average molecular weight $\left(\mathrm{M}_{\mathrm{w}}\right)$ of 30,302 and 50,191 $\mathrm{g} \mathrm{mol}^{-1}$, respectively, a dispersity $\left(\mathrm{M}_{\mathrm{n}} / \mathrm{M}_{\mathrm{w}}\right)$ of 1.656 , and an intrinsic viscosity of $0.3003 \mathrm{dL} \mathrm{g}^{-1}$. The degree of sulfation was calculated from the sulfur content $(17.6 \%)$ provided by the supplier and it was found to be 2.24. The DexS weight average molecular weight $\left(\mathrm{M}_{\mathrm{w}}\right)$ was used for calculating the DexS to Pram molar ratio in the nanoparticles.

\section{Preparation and characterization of polyelectrolyte nanoparticles}

In this study, a suitable concentration range for the spontaneous formation of nanoparticles was previously identified by varying the concentration of DexS between $4.00 \times 10^{-6}$ and $2.00 \times 10^{-5} \mathrm{~mol} \mathrm{~L}^{-1}$ and keeping the concentration of Pram at constant $1.25 \times 10^{-4} \mathrm{~mol} \mathrm{~L}^{-1}$, which corresponds to a DexS/Pram molar ratio varying from $3.20 \times 10^{-2}$ to $1.60 \times 10^{-1}$. The Tyndall effect, characteristic of nanoparticle dispersions, was observed at a DexS concentration of $1.20 \times 10^{-5} \mathrm{~mol} \mathrm{~L}^{-1}$, whereas macroscopic aggregates were formed at lower DexS concentrations $\left(4.00 \times 10^{-6}\right.$ and $\left.8.00 \times 10^{-6} \mathrm{~mol} \mathrm{~L}^{-1}\right)$ and transparent solutions were obtained at higher DexS concentrations $\left(1.60 \times 10^{-5}\right.$ and $\left.2.00 \times 10^{-5} \mathrm{~mol} \mathrm{~L}^{-1}\right)$. The formation of macroscopic aggregates occurred due to the presence of an excess of the peptide. It is most likely that intrapolymer complexes are firstly formed by the complexation of a single dextran molecule with several peptide molecules. Aggregation of these primary complexes by the formation of interpolymer complexes then takes place, causing in turn precipitation of the complexes from the colloidal dispersion. ${ }^{33}$

Once the DexS and Pram concentrations were established, the polyelectrolyte nanoparticles were prepared at a DexS/Pram molar ratio varying from $2.40 \times 10^{-2}$ to $5.30 \times 10^{-2}$, which corresponds to a charge ratio varying from 1.63 to 3.66. Charge ratio was calculated from the molar charge densities of DexS and Pram, which were equal to $5.50 \times 10^{-3}$ (ca. 275.5 negative residues $\mathrm{mol}^{-1}$, sulfur content of $17.6 \%$ ) and $1.01 \times 10^{-6} \mathrm{~mol}$ charge $\mathrm{mg}^{-1}$ (ca. 4 positive residues $\mathrm{mol}^{-1}$ at $\mathrm{pH} 4.0$ ), respectively. These polyelectrolyte nanoparticle dispersions displayed mean particle sizes between 200 and $400 \mathrm{~nm}$, PdI between 0.20 and 0.25 , and zeta potential ranging from -30 to $-40 \mathrm{mV}$ (Table 1). Negative zeta potential indicated the presence of the DexS polyanion at the particle surface, and the net surface charge obtained can be considered sufficient to provide physically stable colloidal dispersions. The theoretical Pram concentration in the nanodispersions varied from $1.19 \times 10^{-4}$ to $1.69 \times 10^{-4} \mathrm{~mol} \mathrm{~L}^{-1}$, and the association efficiency, evaluated by fluorescamine assay (Figure S1 in the Supplementary Information (SI) section), was near $100 \%$ for all DexS/Pram ratios tested. Neither zeta potential nor Pram association efficiency was affected by increasing charge ratio. This can be related to the narrow range of DexS/Pram molar ratios in which nanoparticles were obtained in this study.

Table 1. Composition, physicochemical properties, and drug association of DexS/Pram NPs

\begin{tabular}{|c|c|c|c|c|c|c|}
\hline \multirow{2}{*}{$\begin{array}{l}\operatorname{Pram}^{\mathrm{a}} / \\
(\mathrm{mol} \mathrm{L} \\
\end{array}$} & \multirow{2}{*}{$\begin{array}{c}\text { DexS / } \\
\left(\mathrm{mol} \mathrm{L}^{-1}\right) \times 10^{-6} \\
\end{array}$} & \multirow{2}{*}{$\begin{array}{c}\text { DexS/Pram } \\
\text { molar ratio } \times 10^{-2}\end{array}$} & \multirow{2}{*}{$\begin{array}{l}\text { DexS/Pram } \\
\text { charge ratio }\end{array}$} & \multicolumn{3}{|c|}{ DexS/Pram NP } \\
\hline & & & & $\mathrm{PdI}^{\mathrm{b}} / \mathrm{nm}$ & Zeta potential / mV & Pram AE/ \% \\
\hline 1.69 & 3.98 & 2.36 & 1.63 & $281 \pm 113(0.23)$ & $-36 \pm 4$ & $>99$ \\
\hline 1.56 & 4.60 & 2.95 & 2.03 & $262 \pm 31(0.23)$ & $-31 \pm 2$ & $>99$ \\
\hline 1.45 & 5.13 & 3.54 & 2.44 & $208 \pm 20(0.22)$ & $-33 \pm 1$ & $>99$ \\
\hline 1.35 & 5.58 & 4.13 & 2.85 & $210 \pm 11(0.22)$ & $-41 \pm 2$ & $>99$ \\
\hline 1.27 & 5.98 & 4.72 & 3.25 & $229 \pm 10(0.23)$ & $-33 \pm 3$ & $>99$ \\
\hline 1.19 & 6.33 & 5.31 & 3.66 & $236 \pm 5(0.23)$ & $-40 \pm 2$ & $>99$ \\
\hline
\end{tabular}

${ }^{a}$ Theoretical concentration; ${ }^{\text {in }}$ parenthesis: polydispersion index. Pram: pramlintide; DexS: dextran sulfate; NP: nanoparticles; PdI: particle diameter; AE: pramlintide association efficiency. 

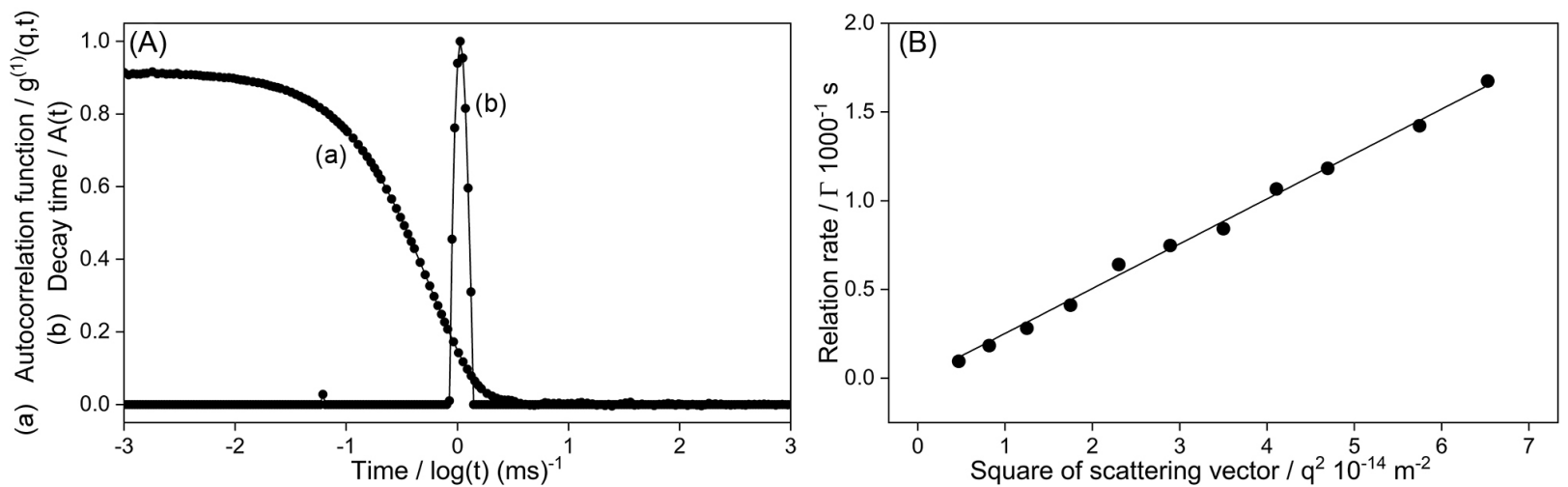

Figure 2. (A) (a) Autocorrelation function $\mathrm{g}^{(1)}(\mathrm{q}, \mathrm{t})$ and (b) distribution function of decay time $\mathrm{A}(\mathrm{t})$ obtained by CONTIN method at scattering angle $90^{\circ}$ and 298.15 K for DexS/Pram NPs in water. The slow modes represent $99 \%$ of the population. (B) Dependence of the relation rate on the square of scattering vector $\mathrm{q}^{2}$ for DexS/Pram NPs at different scattering angles (varying from 30 to $140^{\circ}$ ). Continuous lines correspond to linear fits with intercept at the origin and a correlation coefficient of 0.9994 .

Considering the monodisperse distribution of particle size obtained by backscattering analysis, which is required to ensure adequate and reproducible absorption of the peptide through the absorptive mucosa, further characterization studies were carried out using polyelectrolyte NPs prepared at a DexS/Pram molar ratio of $3.54 \times 10^{-2}$ (Figure S2 in the SI section). The charge ratio in this case of 2.44 was away from charge stochiometric conditions, as described to be required to form stable polyelectrolyte nanoparticles. ${ }^{34-36}$ The hydrodynamic radius of the nanoparticles $\left(\mathrm{R}_{\mathrm{h}}^{\mathrm{NP}}\right)$ was determined by multi-angle DLS at scattering angles between $30^{\circ}$ and $140^{\circ}$. Figure $2 \mathrm{~A}$ shows the correlation function $\mathrm{g}^{(1)}(\mathrm{q}, \mathrm{t})$ and the decay time distribution $\mathrm{A}(\mathrm{t})$ of the nanoparticles obtained at a scattering angle of $90^{\circ}$. A bimodal distribution can be seen, with fast and slow relaxation modes attributed to the dispersity of DexS/Pram nanoparticles. The multi-angle DLS analysis showed a consistent diameter with the backscattering analysis $(208.4 \pm 20.4 \mathrm{~nm}$ against $194.8 \pm 5.8 \mathrm{~nm})$. From the CONTIN analysis of each correlation function, the relaxation time $\tau$ was obtained and the angular dependency of the relation frequency $\Gamma\left(\Gamma=\tau^{-1}\right)$ estimated and plotted against $\mathrm{q}^{2}$ function (Figure 2B). The linear fitting in multiangle to size correlation suggests that polyelectrolyte nanoparticles have a spherical form and a homogeneous size distribution, maintaining their size constant independent of settled angle. The $\mathrm{R}_{\mathrm{h}}^{\mathrm{NP}}$ value of the nanoparticles was found to be $97.4 \pm 2.91 \mathrm{~nm}$. Similar results were found by Frère $e t$ al. ${ }^{35}$ who described the formation of spherical polyelectrolyte nanoparticles by the interaction of the P140 peptide with a polyelectrolyte presenting approximately a 10-fold higher molecular weight. Continuous lines correspond to linear fits with intercept at the origin and a correlation coefficient of 0.9994 .

TEM images of polyelectrolyte DexS/Pram NPs revealed the presence of spherical particles displaying homogeneous size distribution, corroborating data obtained by multi-angle DLS analysis (Figure 3). However, the particle size obtained by Image J software was $43.4 \pm 7.3 \mathrm{~nm}$. This smaller particle size may be attributed to the nanogel character of the DexS/Pram colloidal dispersions, as described elsewhere, ${ }^{34,37,38}$ and to the slower mode viewed in the multi-angle light scattering, which might represent a large portion of the particles population by number. Moreover, when analyzed by TEM, nanogel particles are expected to be smaller than those observed in hydrated conditions due to the water loss during the sample drying.

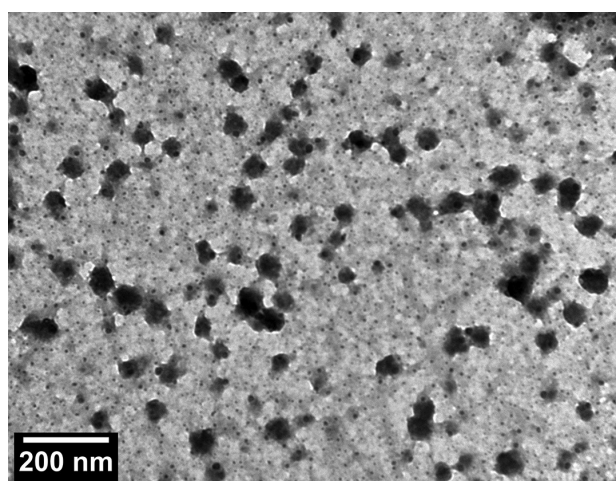

Figure 3. TEM image of DexS/Pram nanoparticles negatively stained with phosphotungstic acid solution $1.0 \%(\mathrm{~m} / \mathrm{v})$, bar $200 \mathrm{~nm}$.

\section{Study of supramolecular interactions}

\section{Fluorescence quenching}

Supramolecular interactions between DexS and Pram were investigated by fluorescamine assay. Fluorescamine, a heterocyclic dione, reacts with primary amines to form a fluorescent product. Pram has a single primary amine, located in its Lys-1 amino acid. Since negatively charged DexS is thought to interact with the positively charged Lys of the Pram molecule, the effect of DexS addition on 

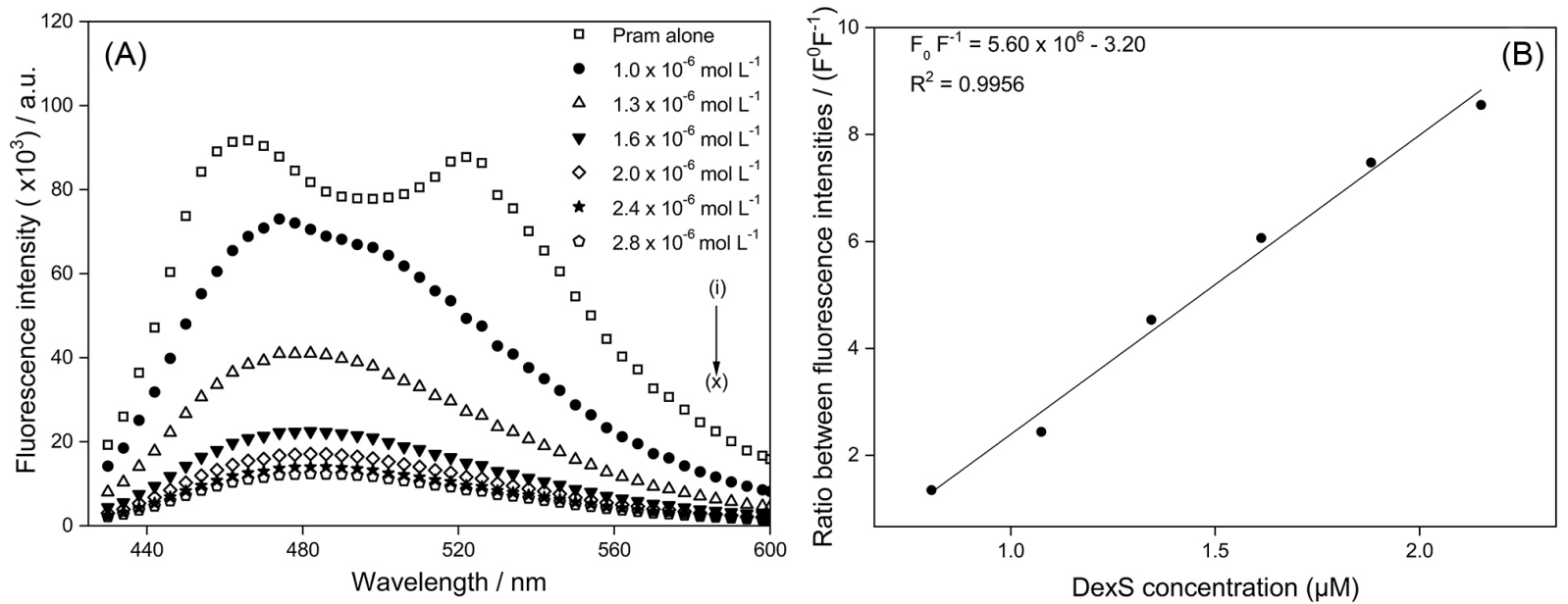

Figure 4. (A) Fluorescence quenching of pramlintide with several concentrations of DexS. Spectra from (i) to (x) correspond to DexS concentrations of $1.00 \times 10^{-6}$ to $2.80 \times 10^{-6} \mathrm{~mol} \mathrm{~L}^{-1}$, at a constant pramlintide concentration of $7.25 \times 10^{-5} \mathrm{~mol} \mathrm{~L}^{-1}\left(1.45 \times 10^{-4} \mathrm{~mol} \mathrm{~L}^{-1}\right.$ diluted 1:2 v/v, with ultrapure water), and (B) Stern-Volmer plot of fluorescence quenching of pramlintide with DexS. Stern-Volmer constant $\mathrm{K}_{\mathrm{Sv}}$ or binding constant $\mathrm{K}=5.60 \times 10^{6} \mathrm{~L} \mathrm{~mol}^{-1}$.

the fluorescence of the Pram-fluorescamine product was investigated. As can be seen in Figure 4A, the fluorescence of the samples decreased linearly upon the addition of increasing concentrations of DexS, from $1.00 \times 10^{-6}$ to $2.80 \times 10^{-6} \mathrm{~mol} \mathrm{~L}^{-1}$. Higher DexS concentrations were also tested, but its effect in fluorescence quenching was negligible, probably because the Pram binding sites were already occupied (data not shown). Quenching data were fitted to the Stern-Volmer equation to give a linear curve $\left(\mathrm{F}_{0} \mathrm{~F}^{-1}=5.60 \times 10^{6}(\mathrm{Q})-3.20\right)$ with a correlation coefficient of 0.9956 (Figure 4B). Assuming the binding of DexS to Pram is a static rather than a dynamic process, the binding constant was found to be $5.60 \times 10^{6} \mathrm{~L} \mathrm{~mol}^{-1}$, which is comparable with values reported in the literature for other polysaccharide-peptide complexes. ${ }^{39,40}$

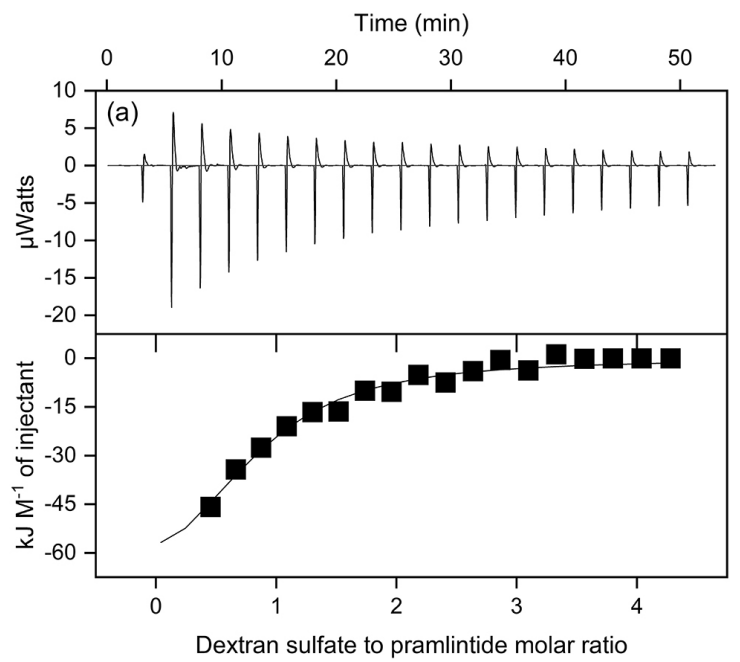

Isothermal titration calorimetry (ITC)

The ITC technique has emerged as an important tool for the examination of the thermodynamic properties of biomacromolecule binding interactions and synthetic polyelectrolyte aggregation by determining the equilibrium constants, stoichiometry, and binding partners under defined experimental conditions. Here, the thermodynamic parameters of the DexS-Pram interactions in the polyelectrolyte nanoparticles were obtained by fitting the binding isotherms (integrated titration peaks corrected for the heats of dilution) to the one-site binding model (Figure 5). The binding affinity constant $(\mathrm{K})$ obtained by titrating the peptide into a DexS solution was $2.45 \times 10^{5} \mathrm{~L} \mathrm{~mol}^{-1}$, similar to that obtained in other mechanistic studies of polysaccharide-peptide complex formation, e.g., for dextran sulfate-parathyroid

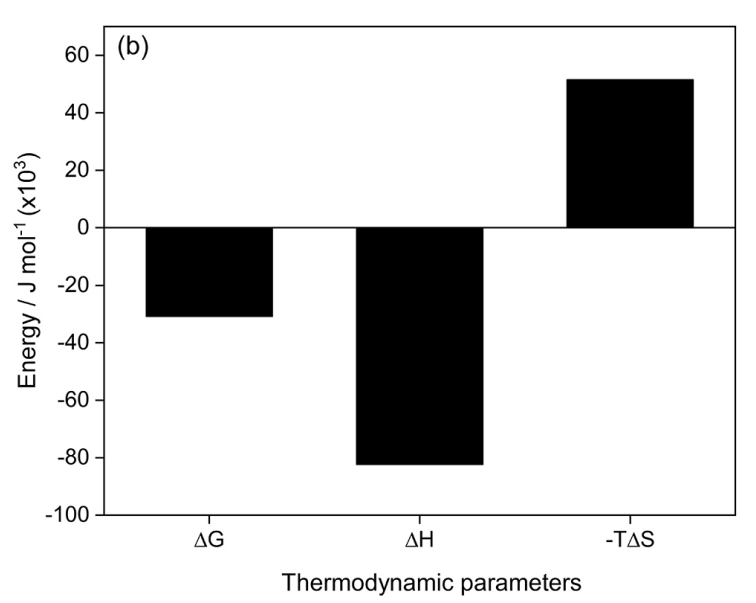

Figure 5. (a) Isothermal titration calorimetry profile of Pram $\left(2.50 \times 10^{-4} \mathrm{~mol} \mathrm{~L}^{-1}\right.$ solution $)$ titrated with DexS solution $\left(1.20 \times 10^{-5} \mathrm{~mol} \mathrm{\textrm {L } ^ { - 1 }}\right.$ solution $)$ at the temperature of $298.15 \mathrm{~K}$, and (b) thermodynamic parameters of interactions in the DexS/Pram nanoparticles obtained by fitting the binding isotherms to the one-site binding model. 
hormone $\left(1.90 \times 10^{6} \mathrm{~L} \mathrm{~mol}^{-1}\right),{ }^{41}$ and fucoidan-protamine polypeptide $\left(2.07 \times 10^{6} \mathrm{~L} \mathrm{~mol}^{-1}\right)$ complexes. ${ }^{42}$ The titrations indicated an exothermic interaction process as expected for an electrostatic interaction of oppositely charged compounds (Figure 5a). Polyelectrolyte nanoparticle formation was produced with spontaneous energy $\left(\Delta \mathrm{G}=-30.85 \mathrm{~kJ} \mathrm{~mol}^{-1}\right)$, in a process driven by an enthalpic contribution $\left(\Delta \mathrm{H}=-82.43 \mathrm{~kJ} \mathrm{~mol}^{-1}\right) .^{41,43}$ Favorable enthalpic binding is characteristic of non-covalent electrostatic interactions, as well as of hydrogen bonding formed by attractive dipole-dipole interactions between Pram and DexS. Besides, DexS/Pram NP formation involves more conformational changes, as indicated by the unfavorable entropy $\left(-\mathrm{T} \Delta \mathrm{S}=+51.58 \mathrm{~kJ} \mathrm{~mol}^{-1}\right.$, Figure $\left.5 \mathrm{~b}\right)$. This effect could originate from the loss in biopolymer conformational freedom after complexation, or that the peptide is very flexible and undergoes a conformational change in the binding process. ${ }^{43,44}$

\section{Fourier-transform infrared spectroscopy (FTIR) and circular dichroism (CD)}

FTIR spectra were obtained for Pram, DexS, and DexS/Pram NPs at wavelengths ranging from 1,800 to $1,000 \mathrm{~cm}^{-1}$, but overlapping peaks of DexS and Pram in FTIR spectra hampered the analysis of the secondary structure of the peptide in higher wavenumbers (data not shown). However, in the amide III region (Figure 6), it was possible to identify peaks that can be related to the Tyr ring vibration $\left(1,265-1,270 \mathrm{~cm}^{-1}\right.$ and $\left.1,180 \mathrm{~cm}^{-1}\right)$ or the turn structure of the peptide (between 1,260 and $1,280 \mathrm{~cm}^{-1}$ ) in both spectra of Pram and DexS/Pram NPs (Figures 6a and $6 \mathrm{c}$, respectively). Also, a small negative peak at $1,315 \mathrm{~cm}^{-1}$ in that of DexS/Pram NPs (Figure 6c) can be related to the $\alpha$-helix peptide structure.

Circular dichroism (CD) experiments give information about the three-dimensional structure of macromolecules containing chiral centers, using circularly polarized light, and it has been considered a powerful technique for studying the secondary structure of peptides. The CD spectrum of unordered peptides is usually characterized by a single band below $200 \mathrm{~nm}$, while $\alpha$-helices structures usually display large $\mathrm{CD}$ bands with negative ellipticity at 222 and $208 \mathrm{~nm}$ along with a positive ellipticity at $193 \mathrm{~nm}$, and $\beta$-sheets exhibit a broad negative band near $218 \mathrm{~nm}$ and a large positive band near $195 \mathrm{~nm}$.

The CD spectra obtained for the Pram solution and DexS/Pram complexes (pH 4.0) are depicted in Figure 7. Pram CD spectrum exhibited a negative peak near $200 \mathrm{~nm}$, characteristic of unordered structures. Unlike the Pram alone, the assembly of the peptide with DexS seemed to lead to the formation of hybrid coiled-coil-like structures, thus

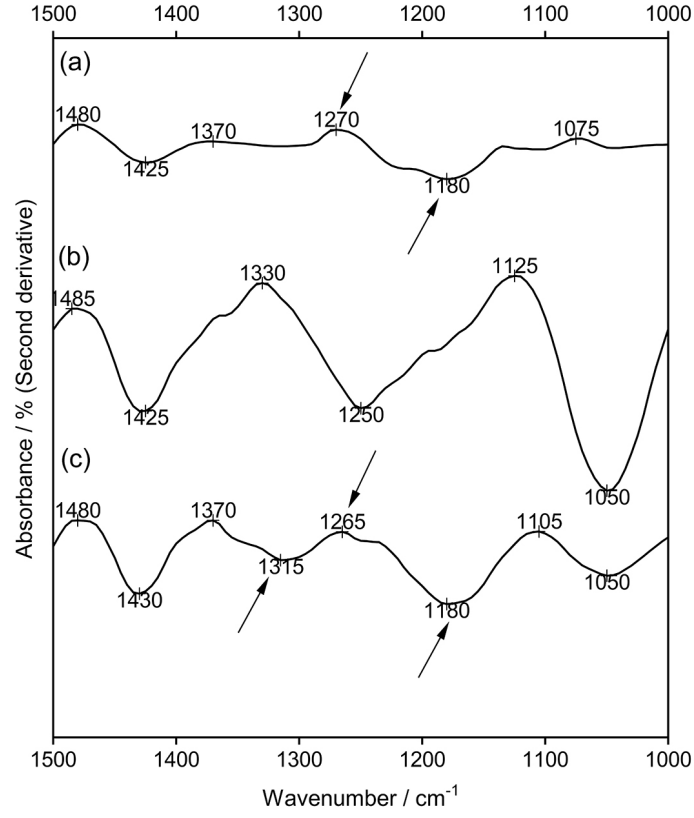

Figure 6. FTIR spectra of (a) Pram, (b) DexS, and (c) DexS/Pram NPs. Peaks related to the Tyr ring vibration $\left(1,265-1,270 \mathrm{~cm}^{-1}\right.$ and $\left.1,180 \mathrm{~cm}^{-1}\right)$ or the turn structure (between 1,260 and $1,280 \mathrm{~cm}^{-1}$ ) are indicated by arrows in (a) and (c). A small negative peak at $1,315 \mathrm{~cm}^{-1}$ related to $\alpha$-helix peptide structure is also indicated by an arrow in (c).

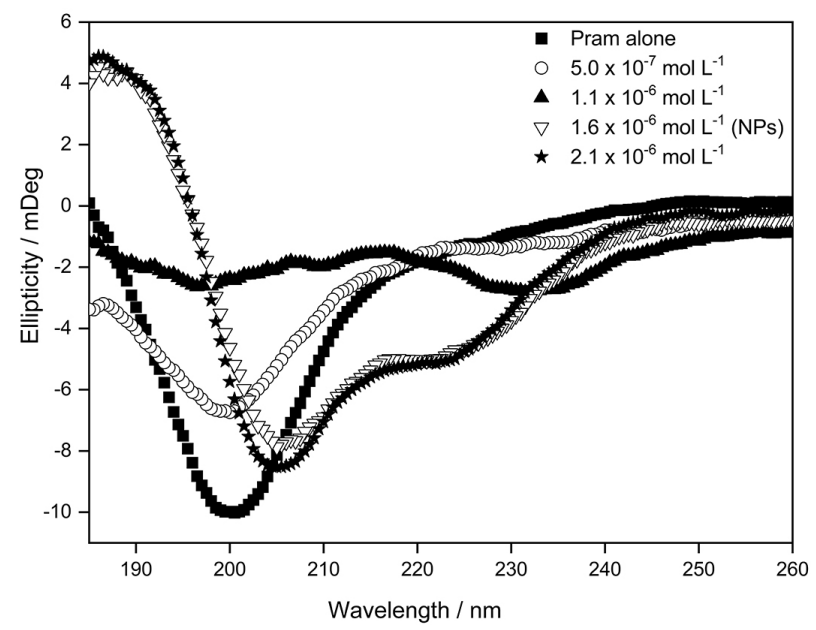

Figure 7. Circular dichroism of DexS/Pram complexes corresponding to a DexS concentration of $5.00 \times 10^{-7}-2.10 \times 10^{-6} \mathrm{~mol} \mathrm{~L}^{-1}$, at constant Pram concentration of $2.90 \times 10^{-5} \mathrm{~mol} \mathrm{~L}^{-1}$ (DexS/Pram NPs diluted 1:5, $\left.1.60 \times 10^{-6} \mathrm{~mol} \mathrm{~L}^{-1} / 2.90 \times 10^{-5} \mathrm{~mol} \mathrm{~L}^{-1}\right)$.

promoting an increase in ellipticity. Based on the analysis carried out using the k2D3 method, Pram in solution contains $5.16 \% \alpha$-helical structure and $11.63 \% \beta$-sheets. This predicted secondary structure content obtained for Pram agreed with that reported elsewhere, ${ }^{45}$ where $68 \%$ disordered structure, $4 \% \alpha$-helix, $13 \% \beta$-sheet, and $11 \%$ turn were found. When DexS/Pram nanoparticles were evaluated, the content of $\alpha$-helical structure increased to $36.25 \%$, while $\beta$-sheet reduced to $6.70 \%$ (Table 2). This pattern was maintained after incubation of the samples 
Table 2. Secondary structure of Pram predicted by $k 2 \mathrm{~d} 3$ webserver ${ }^{30}$ from far-UV circular dichroism (CD) data

\begin{tabular}{|c|c|c|c|c|}
\hline \multirow{2}{*}{ Secondary structure } & \multicolumn{2}{|c|}{ Pram alone (in solution) } & \multicolumn{2}{|c|}{ DexS/Pram NPs } \\
\hline & $\mathrm{pH} 4.0$ & after incubation at $37^{\circ} \mathrm{C}, \mathrm{pH} 7.0$ & $\mathrm{pH} 4.0$ & after incubation at $37^{\circ} \mathrm{C}, \mathrm{pH} 7.0$ \\
\hline$\alpha$-Helix / \% & $5.16 \pm 0.10$ & $1.09 \pm 0.21$ & $36.25 \pm 1.84$ & $40.09 \pm 4.29$ \\
\hline$\beta$-Sheet / \% & $11.63 \pm 0.15$ & $26.97 \pm 0.62$ & $6.70 \pm 0.15$ & $7.22 \pm 3.73$ \\
\hline
\end{tabular}

Pram: pramlintide; DexS: dextran sulfate; NP: nanoparticles.

previously adjusted to $\mathrm{pH} 7.0$ for $24 \mathrm{~h}$ at $37^{\circ} \mathrm{C}(1,400 \mathrm{~s}$, $310.15 \mathrm{~K}$ ) (Figure S3 in the SI section), suggesting that assembling with DexS stabilizes the peptide in physiological conditions by inducing its helical conformation, which could preclude the formation of amyloid fibrils, ${ }^{46}$ already described to occur when Pram is submitted to extreme conditions. ${ }^{29}$ An increase in ellipticity has been reported to occur in interactions of polysaccharides with other peptides/proteins, enhancing their colloidal stability and maintaining peptide biological activity. ${ }^{41,47}$ Similar patterns were found when novicidin was self-assembled with octenyl succinic anhydride-modified analog of hyaluronic acid to form a nanogel. In this case, the complexation was shown to maintain the antimicrobial properties of the drug, while improving its safety profile when tested in cell cultures ${ }^{48}$ Likewise, glycosaminoglycans located at the cell membrane or in the extracellular matrix are thought to induce helical conformations in GAG-binding peptides and proteins, which may enhance the peptide/protein activity and receptor affinity. ${ }^{41}$ Both inhibition and overstabilization of $\alpha$-helix (between approximately 15 to $30 \%$ of $\alpha$-helix over the time) were already described as alternatives to reduce the amylin proteotoxicity, being the partial helix more prone to amyloid formation. ${ }^{46,49,50}$

Considering the results described here, we can assume that Pram acts by physically crosslinking DexS chains by electrostatic interactions, inducing phase separation and leading to the formation of a coacervate. ${ }^{51-53}$ The macromolecular environment led the peptide to reduce its conformational freedom and to adopt a more compact structure ( $\alpha$-helix instead of a random coil), which is stabilized by electrostatic interactions between DexS and Pram and by inter and intramolecular hydrogen bonds.

\section{Colloidal behavior of DexS/Pram NPs in aqueous saline media}

The colloidal stability of DexS/Pram NPs was assessed by evaluating the parameters of size, PdI, and zeta potential after dilution with $\mathrm{NaCl}$ solution at concentrations of $1.00 \times 10^{-2}, 5.00 \times 10^{-2}, 1.00 \times 10^{-1}$, and $2.00 \times 10^{-1} \mathrm{~mol} \mathrm{~L}^{-1}$ $(1: 10, v / v$, Figure $8 a)$. Ionic strength was expected to affect these physicochemical properties of DexS/Pram NPs by causing charge shielding and resulting in larger particle sizes. Salt may interact electrostatically with the peptide and the polyelectrolyte favoring swelling and dissociation of the particles. This hypothesis was confirmed by dissociation studies (Figure 8b), in which free Pram concentrations, evaluated by liquid chromatography with ultraviolet detection (Figure S4 in the SI section), were higher in stronger ionic diluents, from $1.00 \times 10^{-2}$ to $2.00 \times 10^{-1} \mathrm{~mol} \mathrm{~L}^{-1} \mathrm{NaCl}$. This result indicated that the peptide release from the nanocomplex will be triggered by the body's natural ionic strength, as related elsewhere..$^{54}$ In this case, salts in the surrounding medium can access
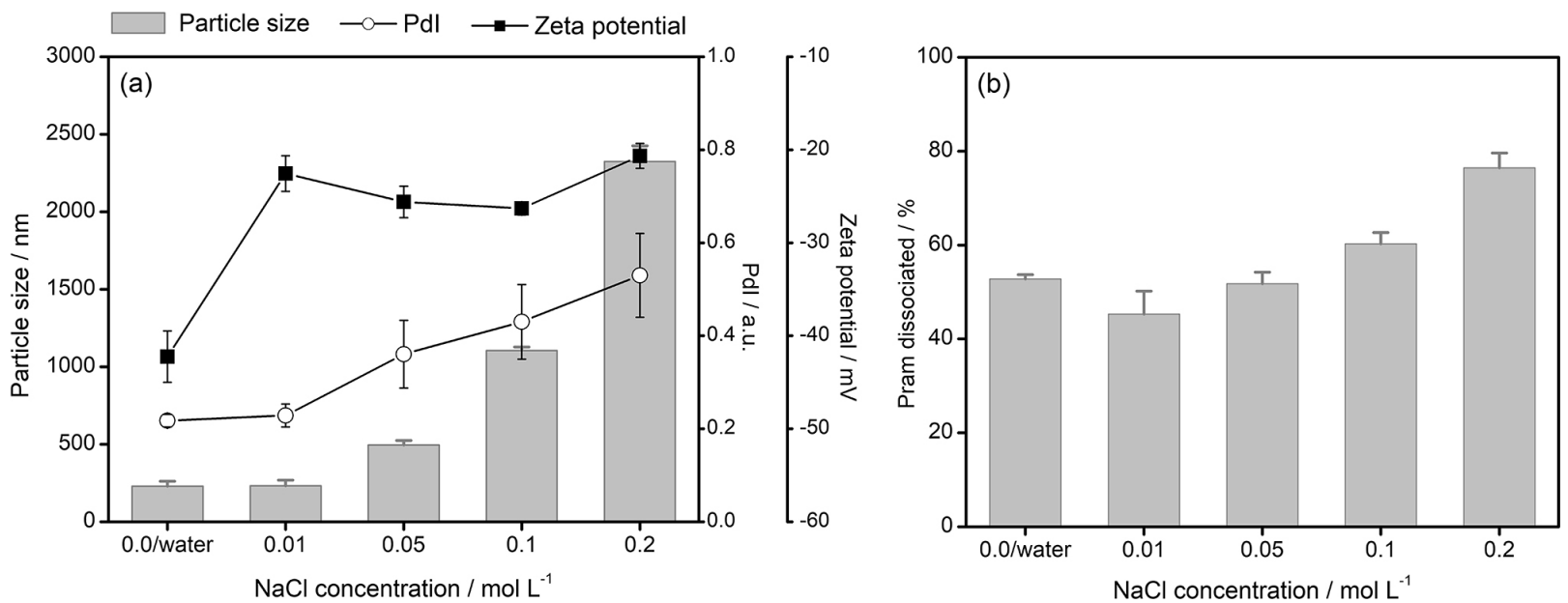

Figure 8. (a) Particle size (PdI) and zeta potential values obtained for DexS/Pram NPs as a function of the NaCl concentration of the medium, and (b) Pram dissociation (\%) as a function of $\mathrm{NaCl}$ concentration of the medium. 
the complex and outcompete the ionic interaction formed between DexS and Pram, leading to dissociation. This feature dramatically affects the Pram release rate from nanoparticles. As can be seen in Figure 9, about 80\% of Pram is released after $48 \mathrm{~h}$ when diluted in ultrapure water, whereas the same amount of the drug is released in the first $2 \mathrm{~h}$, after diluting the samples in SNF. Then, the drug release is governed by drug dissociation from DexS/Pram NPs in biological fluids, where saline concentration is around $1.50 \times 10^{-1} \mathrm{~mol} \mathrm{~L}^{-1}$, and it is considered essential for reaching therapeutically effective concentrations of the peptide after mucosal administration.

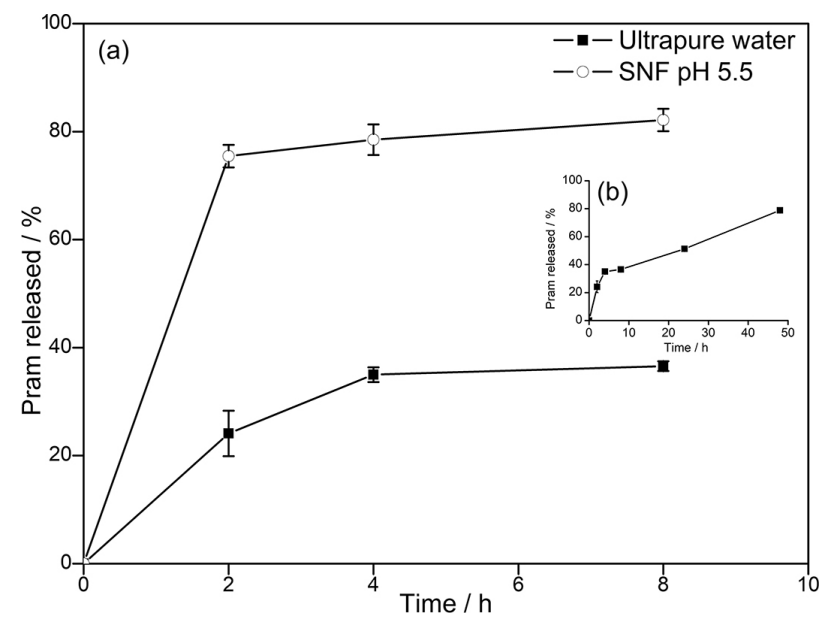

Figure 9. (a) Release profile of Pram from DexS/Pram NPs after dilution of the sample in ultrapure water or SNF pH $5.5(1: 50, \mathrm{v} / \mathrm{v})$ for the first $8 \mathrm{~h}$, and (b) inset shows the Pram release profile from NPs in ultrapure for $48 \mathrm{~h}$.

\section{Conclusions}

This study showed for the first time the feasibility of obtaining DexS/Pram polyelectrolyte nanoparticles with high drug payload, nanometric size, and monodisperse particle size distribution. The formation and the physicochemical properties of DexS/Pram NPs were dependent on the DexS/Pram molar ratio. Supramolecular interactions involved in the DexS/Pram binding were evidenced by different experimental techniques. The high affinity between DexS and Pram, characterized by favorable enthalpic binding, was demonstrated by the fluorescence quenching and ITC experiments. Considering the results described here, we can assume that Pram acts by physically crosslinking DexS chains by electrostatic interactions. Besides, the assembling of the peptide with DexS induced the conformational change of the peptide to the bioactive $\alpha$-helical structure. However, colloidal stability was dependent on the ionic strength of the medium, causing nanoparticle aggregation and peptide dissociation at higher salt concentrations. In this regard, peptide release from the nanocomplex is more likely to occur by dissociation of the complex caused by the body's natural ionic strength. Taken all together, this study brings valuable information about the physicochemical behavior of DexS/ Pram polyelectrolyte nanoparticles that can be useful for developing transmucosal delivery systems for Pram.

\section{Supplementary Information}

Supplementary information including the Pram calibration curves obtained by fluorescamine assay and high performance liquid chromatography, the size distribution profiles of dextran sulfate/pramlintide nanoparticles obtained by backscattering analysis, and the circular dichroism spectrum of Pram and DexS/Pram nanoparticles submitted to incubation for $24 \mathrm{~h}$, at the temperature of $37{ }^{\circ} \mathrm{C}$ and pH 7.0 are available free of charge at http://jbcs.sbq.org.br as PDF file.

\section{Acknowledgments}

This study is part of the National Institute of Science and Technology in Pharmaceutical Nanotechnology: a transdisciplinary approach INCT-NANOFARMA, which is supported by São Paulo Research Foundation (FAPESP), Brazil (grant No. 2014/50928-2), and by National Council for Scientific and Technological (CNPq), Brazil (grant No. 465687/2014-8). The study was also received financial support from National Council for Scientific and Technological (grant No. 425448/2016-2). Carine Zuglianello received a doctoral scholarship from Coordination for the Improvement of Higher Education Personnel (CAPES), Brazil. The authors would like to thank the CEBIME/UFSC and LCME/UFSC for technical support in the circular dichroism and electron microscopy analysis, respectively.

\section{Author Contributions}

Carine Zuglianello conceived the ideas and performed all the experiments, data analysis, and writing of the original draft. Andrés F. Chamorro participated in the performance, analysis, and interpretation of DLS and fluorescence quenching studies. Vanessa A. de Oliveira participated in the performance, analysis, and interpretation of the circular dichroism experiments. Francisco H. Xavier participated in the performance, analysis, and interpretation of the ITC experiments. Elenara Lemos-Senna conceived the ideas. She was responsible for the project administration and funding acquisition. 


\section{References}

1. Yuan, Y.; Li, Y.-B.; Tai, Z.-F.; Xie, Y.-P.; Pu, X.-F.; Gao, J.; J. Food Drug Anal. 2018, 26, 409.

2. Guerreiro, L. H.; Guterres, M. F. A. N.; Melo-Ferreira, B.; Erthal, L. C. S.; Rosa, M. S.; Lourenço, D.; Tinoco, P.; Lima, L. M. T. R.; AAPS PharmSciTech 2013, 14, 1083.

3. Bader, A. R.; Li, T.; Wang, W.; Kohane, D. S.; Loscalzo, J.; Zhang, Y.-Y.; J. Visualized Exp. 2015, 95, e52323.

4. Hay, D. L.; Chen, S.; Lutz, T. A.; Parkes, D. G.; Roth, J. D.; Pharmacol. Rev. 2015, 67, 564.

5. Tam, C. S.; Lecoultre, V.; Ravussin, E.; Expert Opin. Biol. Ther. 2011, 11, 1677.

6. Al-Keilani, M.; Alsmadi, D.; Darweesh, R.; Alzoubi, K.; Clin. Pharmacol. Adv. Appl. 2018, 10, 23.

7. Venkatanarayan, A.; Raulji, P.; Norton, W.; Chakravarti, D.; Coarfa, C.; Su, X.; Sandur, S. K.; Ramirez, M. S.; Lee, J.; Kingsley, C. V.; Sananikone, E. F.; Rajapakshe, K.; Naff, K.; Parker-Thornburg, J.; Bankson, J. A.; Tsai, K. Y.; Gunaratne, P. H.; Flores, E. R.; Nature 2015, 517, 626.

8. Kimura, R.; MacTavish, D.; Yang, J.; Westaway, D.; Jhamandas, J. H.; Mol. Neurobiol. 2017, 54, 748.

9. Tao, Q.; Zhu, H.; Chen, X.; Stern, R. A.; Kowall, N.; Au, R.; Blusztajn, J. K.; Qiu, W. Q.; J. Alzheimers Dis. 2018, 62, 597.

10. Bower, R. L.; Hay, D. L.; Br. J. Pharmacol. 2016, 173, 1883.

11. Wang, H.; Abedini, A.; Ruzsicska, B.; Raleigh, D. P.; Biochemistry 2014, 53, 5876.

12. Anselmo, A. C.; Gokarn, Y.; Mitragotri, S.; Nat. Rev. Drug Discov. 2019, 18, 19.

13. Henchey, L. K.; Jochim, A. L.; Arora, P. S.; Curr. Opin. Chem. Biol. 2008, 12, 692.

14. Zapadka, K. L.; Becher, F. J.; Gomes dos Santos, A. L.; Jackson, S. E.; Interface Focus 2017, 7, 20170030.

15. Perry, S. L.; McClements, D. J.; Molecules 2020, 25, 1161.

16. Yang, M.; Frokjaer, S. In Delivery Technologies for Biopharmaceuticals: Peptides, Proteins, Nucleic Acids and Vaccines; Jorgensen, L.; Nielson, H. M., eds.; John Wiley \& Sons, Ltd: Chichester, UK, 2009, p. 9-28.

17. Zhao, L.; Skwarczynski, M.; Toth, I.; ACS Biomater. Sci. Eng. 2019, 5, 4937.

18. Li, Y.; Wang, Y.; Huang, G.; Gao, J.; Chem. Rev. 2018, 118, 5359.

19. de la Fuente, M.; Csaba, N.; Garcia-Fuentes, M.; Alonso, M. J.; Nanomedicine 2008, 3, 845.

20. Kenley, R. A.; Tracht, S.; Stepanenko, A.; Townsend, M.; L'Italien, J.; AAPS PharmSciTech 2000, 1, 8.

21. Bai, C.; Lao, Z.; Chen, Y.; Tang, Y.; Wei, G.; Front. Chem. 2020, $8,51$.

22. Yu, M.; Every, H. A.; Jiskoot, W.; Witkamp, G.-J.; Buijs, W.; J. Mol. Struct. 2018, 1156, 320.
23. Wu, F.; Zhou, Z.; Su, J.; Wei, L.; Yuan, W.; Jin, T.; Nanoscale Res. Lett. 2013, 8, 197.

24. ChemAxon; Marvin Sketch, 19.18.0; ChemAxon, Hungary, 2019.

25. ALV-Laser Vertriebsgesellschaft $\mathrm{mbH} ; A L V$ Correlator Software, version 3.0.0.17 10/2002; Langen, DE, 2002.

26. Korchagina, E. V.; Philippova, O. E.; Macromolecules 2015 , 48,8622

27. Sze, A.; Erickson, D.; Ren, L.; Li, D.; J. Colloid Interface Sci. 2003, 261, 402.

28. Collins, T. J.; BioTechniques 2007, 43, S25.

29. da Silva, D. C.; Fontes, G. N.; Erthal, L. C. S.; Lima, L. M. T. R.; Biophys. Chem. 2016, 219, 1.

30. Origin 7.0 - MicroCal iTC20; MicroCal, USA, 2015.

31. Louis-Jeune, C.; Andrade-Navarro, M. A.; Perez-Iratxeta, C.; Proteins Struct. Funct. Bioinf. 2012, 80, 374.

32. Jug, M.; Hafner, A.; Lovrić, J.; Kregar, M. L.; Pepić, I.; Vanić, Ž.; Cetina-Čižmek, B.; Filipović-Grčić, J.; J. Pharm. Biomed. Anal. 2018, 147, 350.

33. Xia, J.; Dubin, P. L. In Macromolecular Complexes in Chemistry and Biology; Dubin, P.; Bock, J.; Davis, R.; Schulz, D. N., eds.; Springer Berlin Heidelberg: Berlin, Heidelberg, 1994, p. 247271.

34. Mohtashamian, S.; Boddohi, S.; Hosseinkhani, S.; Int. J. Biol. Macromol. 2018, 107, 2730.

35. Frère, Y.; Danicher, L.; Muller, S. In Peptide Materials; Alemán, C.; Bianco, A.; Venanzi, M., eds.; John Wiley \& Sons: Chichester, UK, 2013, p. 385-415.

36. Umerska, A.; Corrigan, O. I.; Tajber, L.; Carbohydr. Polym. 2017, 156, 276.

37. Xia, L.-W.; Xie, R.; Ju, X.-J.; Wang, W.; Chen, Q.; Chu, L.-Y.; Nat. Commun. 2013, 4, 2226.

38. Khan, A.; El-Toni, A. M.; Alam, J.; Aldalbahi, A.; Ahmed, M.; Labis, J. P.; Ahamad, T.; Hezam, M.; J. Nanomater. 2018, 2018 , 2180518.

39. Xu, A. Y.; Melton, L. D.; Jameson, G. B.; Williams, M. A. K.; McGillivray, D. J.; Soft Matter 2015, 11, 6790.

40. Hu, B.; Wang, S. S.; Li, J.; Zeng, X. X.; Huang, Q. R.; J. Phys. Chem. B 2011, 115, 7515.

41. Kamerzell, T. J.; Joshi, S. B.; McClean, D.; Peplinskie, L.; Toney, K.; Papac, D.; Li, M.; Middaugh, C. R.; Protein Sci. 2007, 16, 1193.

42. Lu, K.-Y.; Li, R.; Hsu, C.-H.; Lin, C.-W.; Chou, S.-C.; Tsai, M.-L.; Mi, F.-L.; Carbohydr. Polym. 2017, 165, 410.

43. Hadian, M.; Hosseini, S. M. H.; Farahnaky, A.; Mesbahi, G. R.; Yousefi, G. H.; Saboury, A. A.; Food Hydrocolloids 2016, 55, 108.

44. Cao, Y.; Fang, Y.; Nishinari, K.; Phillips, G. O.; Sci. Rep. 2016, 6, 23739.

45. Nonoyama, A.; Laurence, J. S.; Garriques, L.; Qi, H.; Le, T.; Middaugh, C. R.; J. Pharm. Sci. 2008, 97, 2552. 
46. Bhattacharya, S.; Xu, L.; Thompson, D.; ACS Chem. Neurosci. 2019, 10, 2830.

47. Antonov, Y. A.; Zhuravleva, I. L.; Cardinaels, R.; Moldenaers, P.; Food Hydrocolloids 2018, 74, 227.

48. Water, J. J.; Kim, Y.; Maltesen, M. J.; Franzyk, H.; Foged, C.; Nielsen, H. M.; Pharm. Res. 2015, 32, 2727.

49. Cort, J. R.; Liu, Z.; Lee, G. M.; Huggins, K. N. L.; Janes, S.; Prickett, K.; Andersen, N. H.; Protein Eng. Des. Sel. 2009, 22, 497.

50. Raimundo, A. F.; Ferreira, S.; Martins, I. C.; Menezes, R.; Front. Mol. Neurosci. 2020, 13, 35.
51. Zhang, L.; Furst, E. M.; Kiick, K. L.; J. Controlled Release 2006, 114, 130.

52. Pechar, M.; Pola, R.; Laga, R.; Braunová, A.; Filippov, S. K.; Bogomolova, A.; Bednárová, L.; Vaněk, O.; Ulbrich, K.; Biomacromolecules 2014, 15, 2590.

53. Ristroph, K. D.; Prud'homme, R. K.; Nanoscale Adv. 2019, 1, 4207.

54. Patel, A.; Gaudana, R.; Mitra, A. K.; J. Microencapsulation 2014, 31, 542 .
Submitted: October 8, 2020

Published online: April 27, 2021 